\title{
SiC-Based Hydrogen Selective Membranes for Water-Gas-Shift Reaction
}

\author{
Annual Technical Progress Report \\ Reporting Period: 9/16/01 - 9/15/02
}

Paul K.T. Liu, Principal Investigator

October 31, 2002

Award No. DE-FG26-99FT40683

Media and Process Technology Inc.

1155 William Pitt Way

Pittsburgh, PA 15238

Subcontractor:

University of Southern California

University Park

Los Angeles, CA 90089 


\section{Disclaimer}

This report was prepared as an account of work sponsored by an agency of the United States Government. Neither the United States Government nor any agency thereof, nor any of their employees, makes any warranty, express or implied, or assumes any legal liability or responsibility for the accuracy, completeness, or usefulness of any information, apparatus, product, or process disclosed, or represents that its use would not infringe privately owned rights. Reference herein to any specific commercial product, process, or services by trade name, trademark, manufacturer, or otherwise does not necessarily constitute or imply its endorsement, recommendation, or favoring by the United States government or any agency thereof. The view and opinions of authors expressed herein do not necessarily state or reflect those of the United States Government or any agency thereof. 


\begin{abstract}
$\underline{\text { Abstract: }}$
In the first two years of this project, we focused on the membrane synthesis, characterization and optimization. In the past year, we have concentrated on the product development for improving the efficiency of hydrogen recovery from coal gasifier off-gas via water-gas-shift (WGS) reaction. A mathematical simulation study has been performed to compare the performance of the membrane reactor (MR) vs conventional packed bed rector for WGS reaction. Our result demonstrates that $>99.999 \%$ conversion can be accomplished via WGS-MR using the hydrogen selective membrane developed by us. Further, water/CO ratio can be reduced, and $>97 \%$ hydrogen recovery and $<200 \mathrm{ppm} \mathrm{CO}$ can be accomplished according to the mathematical simulation. Thus, we believe that the operating economics of WGS can be improved significantly based upon the proposed MR concept. In parallel, gas separations and hydrothermal and long-term-storage stability of the hydrogen selected membrane have been experimentally demonstrated using a pilot-scale tubular membrane under a simulated WGS environment. For the remaining period of this project, we will conduct experimental study using the hydrogen selective membrane to verify the performance projected by the mathematical simulation
\end{abstract}




\section{TABLE OF CONTENTS}

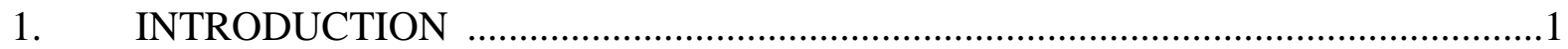

2. EXPERIMENTAL, RESULTS AND DISCUSSION ........................................2

2.1 Characterization of Hydrogen Selective Membrane prepared for WGS ..........2

2.2 Hydrogen Separation using Pilot Scale Hydrogen Selective Membrane ...........6

2.3 Comparison of Membrane vs Conventional Reactor for WGS - Mathematical

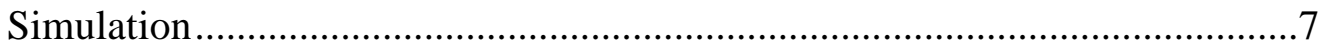

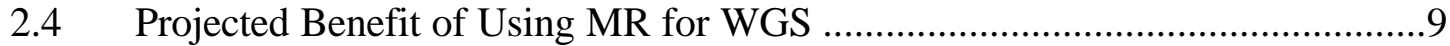

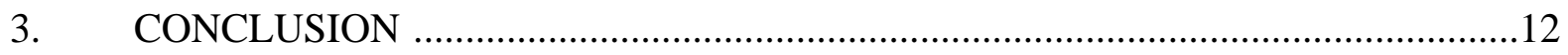

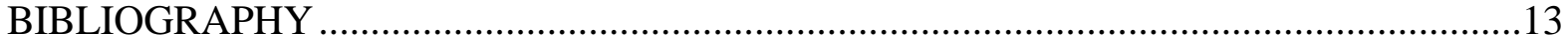

LIST OF ACRONYMS AND ABBREVIATIONS ....................................................14

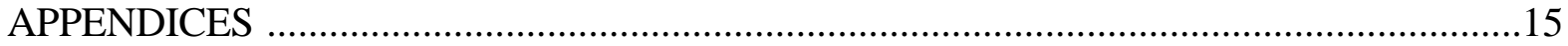

1. Pilot testing facility used for hydrogen recovery from $\mathrm{H}_{2} / \mathrm{CO}$ mixture ...........15 


\section{LIST OF TABLES AND FIGURES}

$\underline{\text { Tables }}$

Table 1 Chemical Stability of Hydrogen Selective Membrane in the presence of organic

$\underline{\text { Figures }}$

Figure 1 Performance of M\&P Hydrogen Selective Membrane (U-130) and its Storage Stability (presented in terms of $\mathrm{H}_{2}$ Permeance). 2

Figure 2 Performance of M\&P Hydrogen Selective Membrane and its Long Term Storage Stability (U-130): in terms of Nitrogen Permeance .3

Figure 3 Hydrothermal Stability Test of M\&P Hydrogen Selective Membrane (200+/-5C with $3+/-0.5$ bar steam) .5

Figure 4 Hydrogen purity plotted as a function of hydrogen recovery for a full-scale M\&P

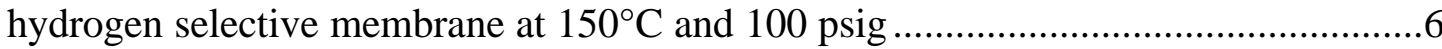

Figure $5 \quad$ CO Conversion in Packed bed vs Membrane Reactor ..........................................8

Figure 6 CO Conversion through WGS: Effect of Steam/CO Ratio.....................................

Figure 7 Effect of Steam/CO ratio for Hydrogen Recovery in Membrane reactor (same condition as above)

Figure 8 CO Concentration in $\mathrm{H}_{2}$ Recovered from Membrane Reactor (same condition as above) 


\section{INTRODUCTION}

In the first two years of this project we have made significant progress in the preparation of a hydrogen selective inorganic membrane suitable for water-gas-shift (WGS) reaction. In Year I we demonstrated the feasibility of preparing a hydrogen selective nanoporous membrane with hydrothermal stability required for WGS. In year II, we conducted a comprehensive membrane optimization study, focusing on the effect of the key synthesis parameters on the performance, selectivity and stability of the membrane. In the past year, we have focused on the product development specific for hydrogen recovery from coal gasifier off-gas via WGS. Our approach includes:

a Perform mathematical simulation for WGS shift reaction to determine benefit potentially delivered by the hydrogen selective membrane developed up to this point.

- Conduct membrane characterization relevant to the proposed WGS reaction environment identified by mathematical simulation.

- Verify hydrogen recovery via the selected hydrogen selective membrane using a pilot scale unit.

This report summarizes the result of the above study. 


\section{EXPERIMENTAL, RESULTS AND DISCUSSION}

\subsection{Characterization of Hydrogen Selective Membrane prepared for WGS}

In this section, we summarize the experimental results obtained from the characterization of the hydrogen selective membrane selected and its hydrothermal stability for the proposed WGS reaction. They are presented as follows:

\section{- Membrane Permeance and Selectivity}

Membrane hydrogen permeances ranging from 0.5 to $>3 \mathrm{~m}^{3} / \mathrm{m}^{2} / \mathrm{hr} / \mathrm{bar}$ have been demonstrated (see Figures 1\&2). Selectivities for $\mathrm{H}_{2}$ to $\mathrm{N}_{2}{ }^{1}$ are 50 to $>200$ even at temperatures in excess of $200^{\circ} \mathrm{C}$ as shown in these figures..

\section{Figure 1 Performance of M\&P Hydrogen Selective Membrane (U-130) and its Storage Stability (presented in terms of $\mathrm{H}_{2}$ Permeance)}

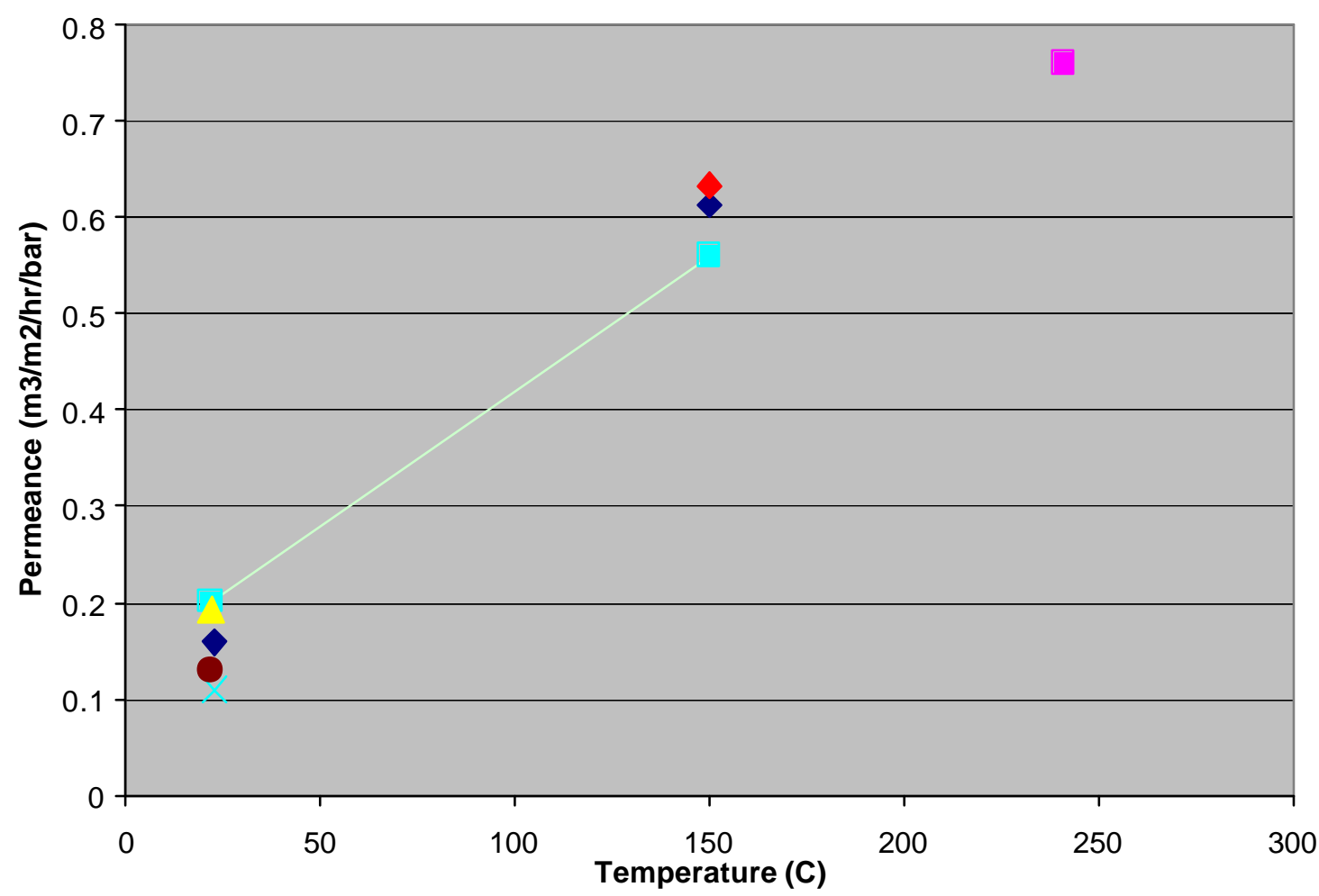
$\longrightarrow$ As freshly prepared, $2 / 28 / 02$
$\longrightarrow$ After Storage (5/24/02)
—-After Storage (3/5/02)
After sotrage (3/20/02)
— After Storage (5/28/02)
__ After Storage (6/11/02, Schenley)
- After Storage (6/12/02, Schenley)
(1) After Storage $(6 / 27 / 02$, Schenley)
After Storage $(8 / 13 / 02)$

\footnotetext{
${ }^{1}$ Nitrogen is used here to represent gas components rejected by this hydrogen selective membrane, including $\mathrm{CO}_{2}$ and $\mathrm{CO}$. Water, as $\mathrm{H}_{2}$, is permeable through the membrane.
} 


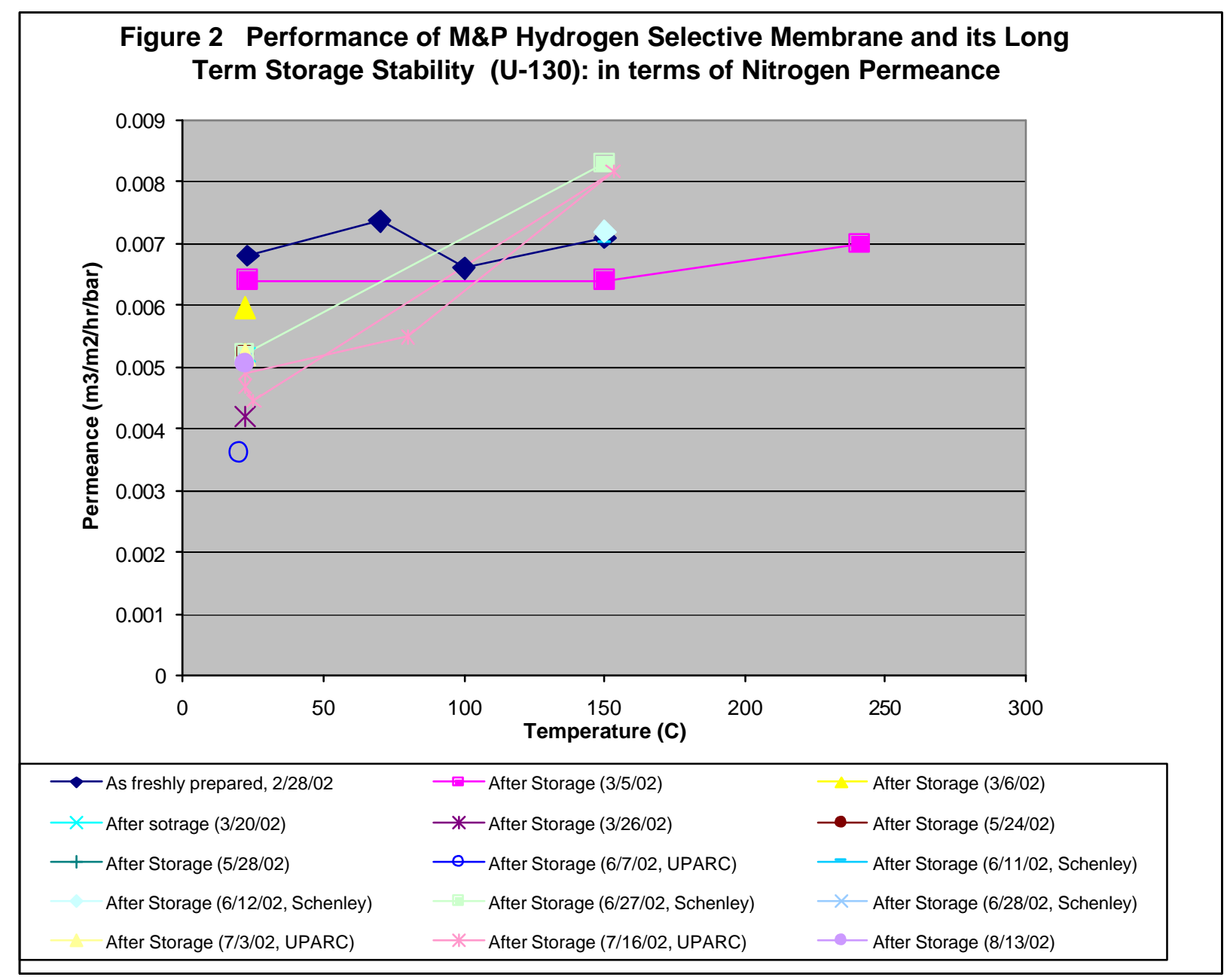




\section{Hydrothermal and Chemical Stability}

The hydrogen selective membrane has demonstrated excellent hydrothermal stability under the WGS condition we selected as shown in Figure 3. The table below shows the $\mathrm{H}_{2}$ permeance of an M\&P's membrane at 80 and $180^{\circ} \mathrm{C}$ before and after exposure for eight hours to a stream of helium saturated with hexane at $40^{\circ} \mathrm{C}(\sim 150,000 \mathrm{ppmv}$ hexane $)$. At an operating temperature of $80^{\circ} \mathrm{C}$, the $\mathrm{H}_{2}$ permeance falls by about $70 \%$. This compares with a reduction of $<20 \%$ at $180^{\circ} \mathrm{C}$. Further, the membrane selectivity is also reduced significantly at the lower operating temperature, but is unchanged at $180^{\circ} \mathrm{C}$. Hence, the membrane performance is stable at high operating temperatures in the presence of very high concentrations of condensable organic vapors. In addition, our hydrogen selective membrane has shown no aging effect during the 6-month storage test as shown in Figures $1 \& 2$.

Table 1 Chemical Stability of Hydrogen Selective Membrane in the presence of organic vapor

\begin{tabular}{|c|c|c|c|c|}
\hline \multirow{2}{*}{$\begin{array}{c}\text { Operating } \\
\text { Temperature } \\
{\left[{ }^{\circ} \mathrm{C}\right]}\end{array}$} & \multicolumn{2}{|c|}{ Before Exposure to He/Hexane } & \multicolumn{2}{|c|}{$\begin{array}{c}\text { At the End of the } \mathrm{He} / \mathrm{Hexane} \\
\text { Exposure Test }\end{array}$} \\
\hline & $\begin{array}{c}\text { Hydrogen } \\
\text { Permeance } \\
{\left[\mathrm{m}^{3} / \mathrm{m}^{2} / \mathrm{hr} / \mathrm{bar}\right]}\end{array}$ & $\begin{array}{c}\mathbf{H}_{2} / \mathbf{N}_{2} \\
\text { Selectivity } \\
{[-]} \\
\end{array}$ & $\begin{array}{c}\text { Hydrogen } \\
\text { Permeance } \\
{\left[\mathrm{m}^{3} / \mathbf{m}^{2} / \mathrm{hr} / \mathrm{bar}\right]}\end{array}$ & $\begin{array}{c}\mathbf{H}_{2} / \mathbf{N}_{2} \\
\text { Selectivity } \\
{[-]} \\
\end{array}$ \\
\hline 180 & 0.775 & 53.1 & 0.626 & 56.9 \\
\hline 80 & 0.439 & 67.6 & 0.134 & 24.4 \\
\hline
\end{tabular}


Figure 3 Hydrothermal Stability Test of M\&P Hydrogen Selective Membrane $(200+/-5 \mathrm{C}$ with $3+/-0.5$ bar steam)

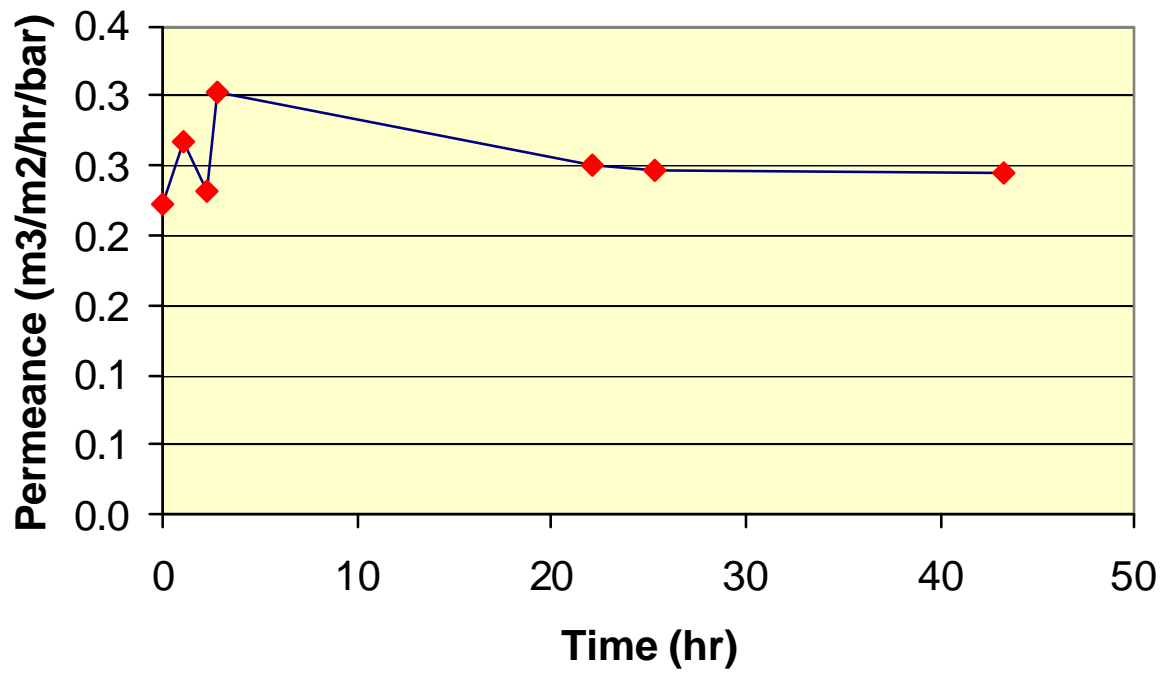

$-\rightarrow$ He permeance measured in the presence of steam after $0 \mathrm{hr}$ 


\subsection{Hydrogen Separation using Pilot Scale Hydrogen Selective Membrane}

Figure 4 below shows the separation efficiency of one of M\&P's full-scale hydrogen selective membranes generated from a pilot testing facility. The purity of hydrogen produced is plotted as a function of the percent of hydrogen recovered from a feed stream containing $\mathrm{H}_{2} / \mathrm{CO}$ at 50/50. High recovery of hydrogen is important and, as this figure shows, it is possible to recover $90 \%$ of the hydrogen in the feed gas at a product purity of $\sim 90 \% \mathrm{H}_{2}$. This stream represents the actual stream generated from our client's high temperature waste conversion process. In the WGS reaction, $\mathrm{H}_{2}$ purity in excess of $99 \%$ is feasible as demonstrated in Figure 8 by coupling a similar stream generated from the coal gasifier with a water-gas-shift reaction. Due to our substantial pilot scale experience in the separation of $\mathrm{H} 2 / \mathrm{CO}$ stream using an inorganic membrane at a high temperature, we are confident to deliver a similar success in the proposed pilot test (Task 7) once the reactor is designed, and tested. Our existed pilot plant facility prepared for this bench scale test is shown in Appendix.

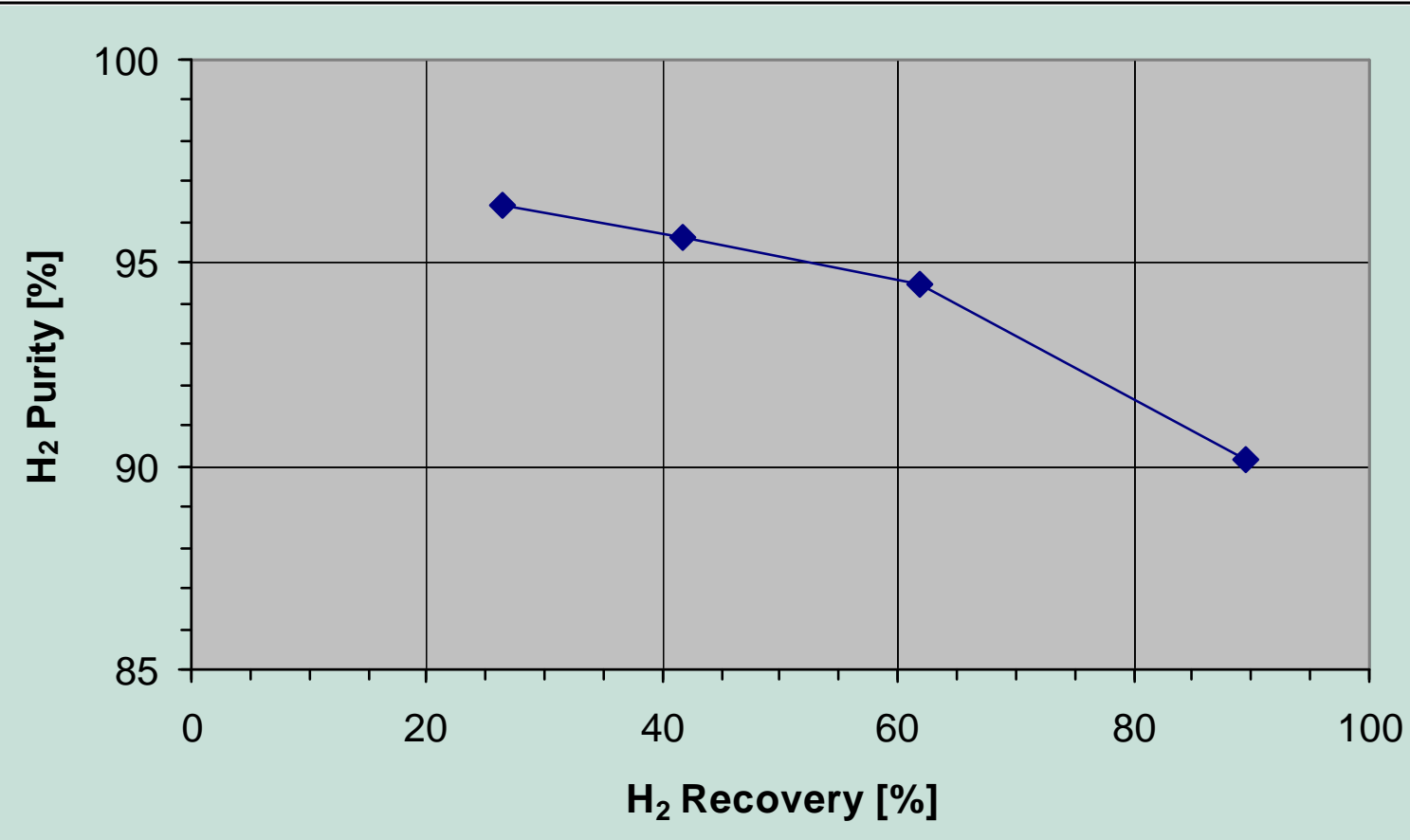

Figure 4 Hydrogen purity plotted as a function of hydrogen recovery for a full-scale M\&P hydrogen selective membrane at $150^{\circ} \mathrm{C}$ and $100 \mathrm{psig}$. The feed is $50 / 50 \mathrm{H}_{2} / \mathrm{CO}$. The hydrogen permeance is $0.69 \mathrm{~m}^{3} / \mathrm{m}^{2} / \mathrm{hr} / \mathrm{bar}$ and selectivity of $\mathrm{H}_{2} / \mathrm{CO}$ is 71 of the membrane used in this example. 


\subsection{Comparison of Membrane vs Conventional Reactor for WGS - Mathematical Simulation}

Presently, WGS is implemented in a two-stage operation. A high temperature shift reactor (HTS) is operated at $\sim 450^{\circ} \mathrm{C}$ to take advantage of the high reaction rate and deliver about $97 \%$ conversion [1]. Also, excess steam (6 to 10 times stoichiometric requirement) is used to promote conversion and inhibit catalyst coking. Then, a low temperature shift (LTS) at $\sim 200$ to $250^{\circ} \mathrm{C}$ is used to further increase the $\mathrm{CO}$ conversion to $\sim 99.2$ to $99.6 \%$ [1]. Again, excess steam is used to promote equilibrium conversion but coke formation potential is negligible. However, the reaction rate is too low at this low temperature due to the high hydrogen concentration. Yet, if the reaction rate can be enhanced via in-situ removal of hydrogen, the LTS operation is very attractive since:

- Single stage conversion of $\mathrm{CO}$ from 0 to $>99.9 \%$ can be achieved at low temperature - Excess steam can be minimized since coke formation potential is negligible.

- The low reaction rate in LTS can be compensated for via in-situ removal of hydrogen.

The simulation below shows that conversion vs reactor length for a side-by-side conversion (i.e., same superficial space velocity and catalyst loading) of the proposed membrane reactor vs the low temperature shift (LTS) reactor. Both are operated at $250^{\circ} \mathrm{C}$, a maximum operating temperature of existing LTS reactor, and $\mathrm{H}_{2} \mathrm{O} / \mathrm{CO}$ ratio of 6 , the low end of the conventional WGS reaction. Evidently, the packed-bed reactor is very inefficient under LTS conditions due to the low reaction rate in the presence of substantial product hydrogen. Hence, the $2^{\text {nd }}$ stage is only used to improve the conversion of CO typically from 92 to $99 \%$. On the other hand, the MR can selectively permeate hydrogen throughout the entire bed length; thus, the conversion of $\mathrm{CO}$ in the membrane reactor exceeds the packed-bed reactor, i.e., from 0 to $99.9 \%$. In summary, the WGS-MR operated at the LTS range is technically feasible based upon the simulation result here using the rate parameters and operating condition presently practiced for the LTS reactor. 
Fiqure 5 Co Conversion in Packed bed vs Membrane Reactor 250C, 13.6 atm (reactor side), 1 atm (permeate side), $3 \mathrm{sec}$, Sweep Ratio=0.25

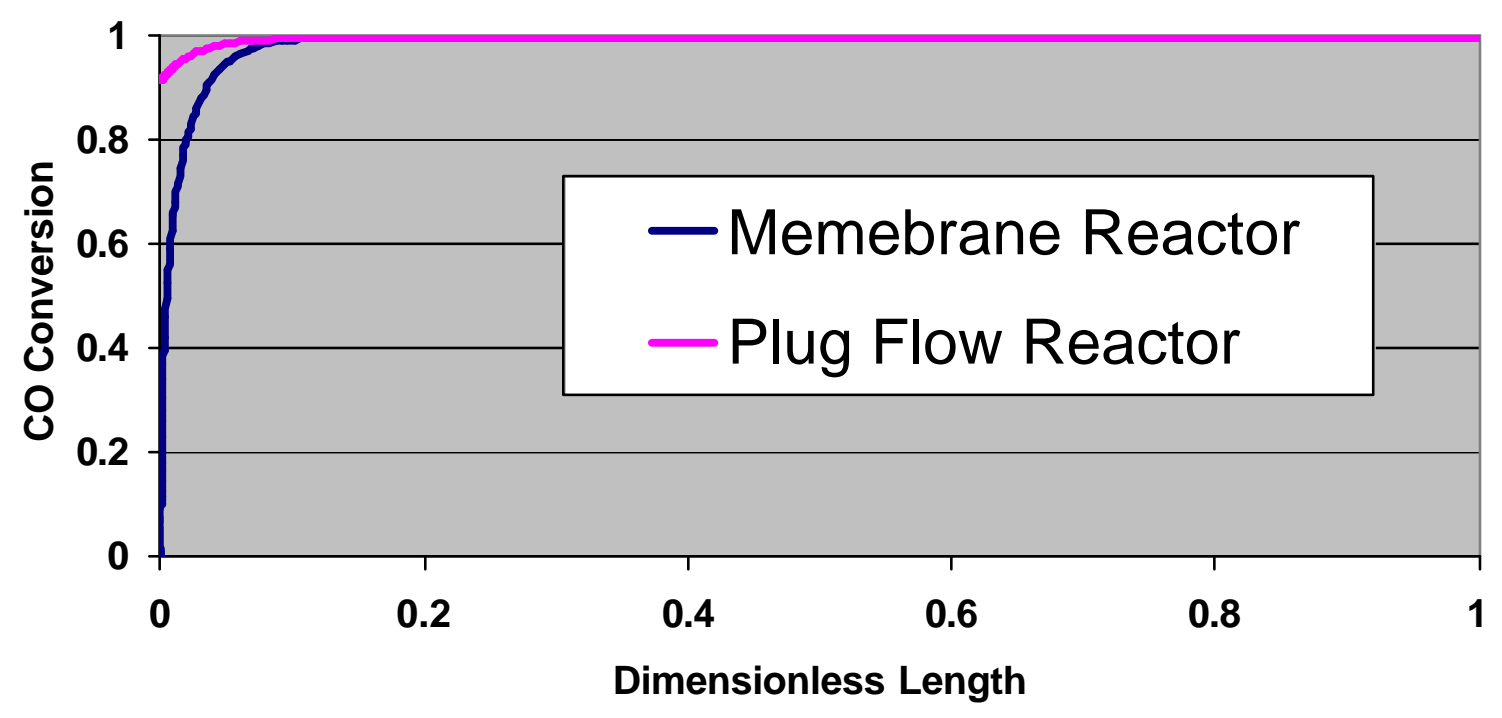




\subsection{Projected Benefit of Using MR for WGS}

The essence of this proposed WGS-MR is its ability to deliver high CO conversion under the mild LTS operating conditions. Thus, the WGS reaction for coalbased power generation can be streamlined to a single stage using one type of catalyst and operated at one temperature as opposed to the conventional use of two different catalysts at two reaction temperatures. In addition to the capital cost savings with this one stage operation at the lower temperature, we have identified additional benefits below:

- Cost Savings via Reduced Steam/CO Ratio. Steam in excess of stoichiometry is not required since coke formation potential is negligible and isothermal operation is simplified using the MR configured as a shell-and-tube heat exchanger. Our simulation below shows the effect of the steam/CO ratio at 6,3 and 1.5 for the membrane reactor and 6 for the packed bed. Evidently, the conversion difference between 1.5 and 6 is modest. In fact, the low ratio favors a high degree of hydrogen recovery as discussed next.

\section{Figure 6 CO Conversion through WGS: Effect of Steam/CO Ratio (same condition as above)}

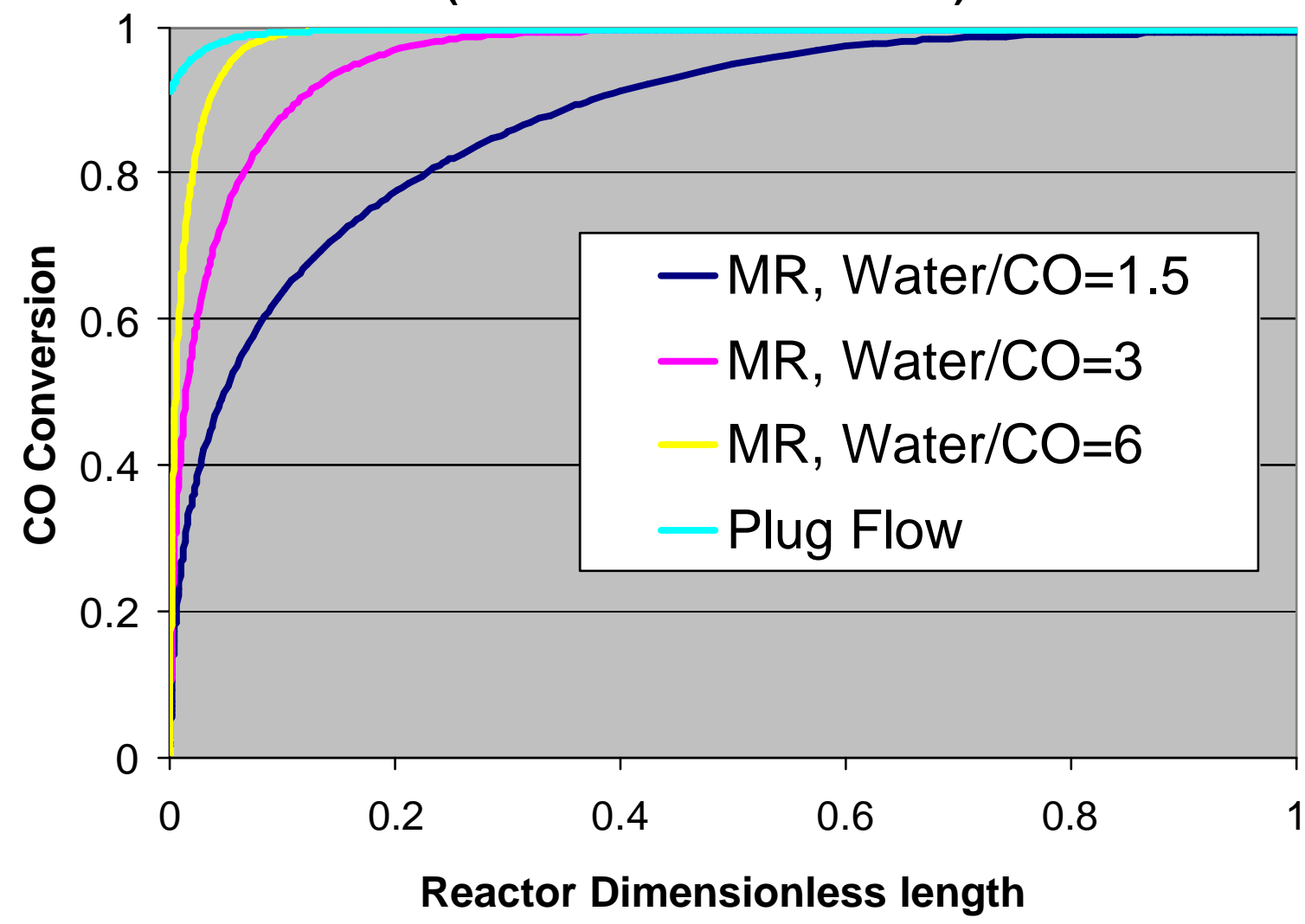


- Hydrogen Recovery with Minimum Parasitic Energy Consumption. In our simulation, about $96 \%$ of the hydrogen is recovered in the MR by sweeping the permeate with steam (at ca. $25 \%$ of the feed). Thus the majority of the $\mathrm{H}_{2}$ can be recovered using a small Amount of near ambient steam. Water can then be knocked out of the hydrogen (and recycled if necessary). Thus, our simulation shows that using WGS-MR, a high degree of hydrogen recovery can be accomplished with minimal parasitic energy consumption.

Figure 7 Effect of Steam/CO ratio for Hydrogen Recovery in Membrane reactor (same condition as above)

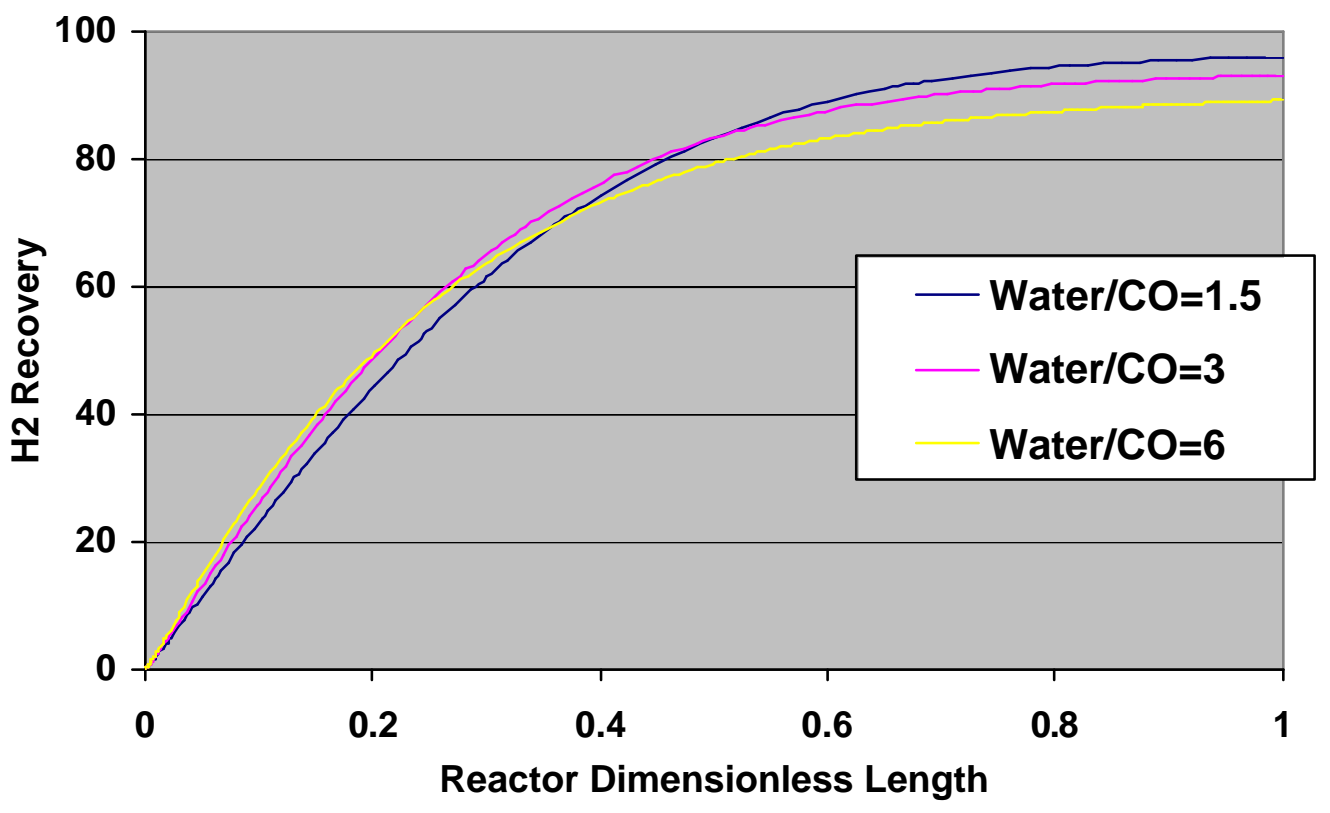


- Trace CO Contamination of the Recovered Hydrogen CO content in the hydrogen product is critical for the down stream power generation via the PEM type fuel cell. Our simulation below indicates that $\mathrm{CO}$ as low as $\sim 200$ ppm can be achieved with the proposed WGS-MR. This trace level of $\mathrm{CO}$ can be post treated with a methanizer or partial oxidizer economically and effectively to reduce it to $<10 \mathrm{ppm}$ to meet the present PEM fuel cell feedstock specification. For comparison, the conventional WGS delivers $\sim 0.3$ mole $\% \mathrm{CO}$ at the exit stream of the LTS reactor [1]. Thus, the cost of post-treatment to meet the fuel cell specification is much reduced in the proposed MR.

a Streamline of Pre-treatment Requirement. No simulation can quantify this benefit although we believe that the potential cost savings are significant.

Figure $8 \mathrm{CO}$ Concentration in H2 Recovered from Membrane Reactor (same condition as above)

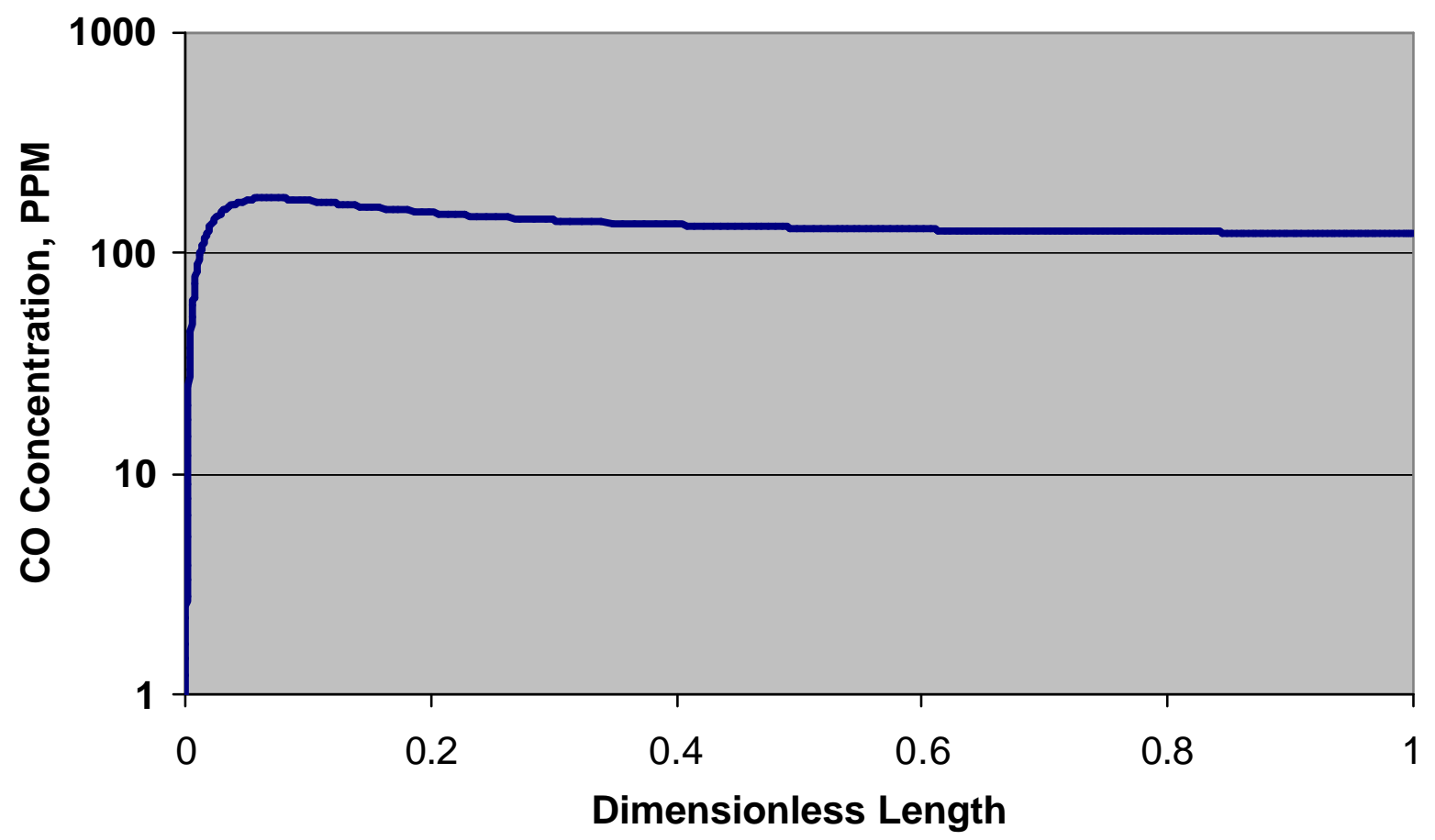




\section{Conclusions}

Our in-house simulation study indicates nearly complete conversion of CO and recovery of hydrogen from the coal gasifier off-gas via the one-stage water-gas-shift (WGS) reaction operated in the LTS range using an MR.

a The main objective of this project is to improve the efficiency (both capital and operating cost) of hydrogen production for coalbased power generation via a commercially ready membrane reactor (MR) for water-gas-shift (WGS) reaction. Specifically we will experimentally demonstrate this highly efficient, robust WGS-MR in the three aspects below:

$\square$ Complete conversion of $\mathrm{CO}$ in a single-stage WGS-MR under mild conditions, i.e., existing low-temperature-shift (LTS) reaction temperature, 200 to $250^{\circ} \mathrm{C}$, and catalyst with a stochiometric steam/CO ratio.

$\square$ Concentration of $\mathrm{CO}_{2}$ in the reject side of $\mathrm{MR}$ for $\mathrm{CO}_{2}$ capture with minimum or no parasitic energy consumptions.

$\square \quad$ Reducing gas clean- up burden via (i) pre-treatment at a manageable temperature, e.g., $250^{\circ} \mathrm{C}$ vs $>450^{\circ} \mathrm{C}$ of existing hot gas clean-up, (ii) no sulfur (and other contaminants) removal requirement in the pre-treatment, and (iii) combining contaminant (such as sulfur and others) removal with the $\mathrm{CO}_{2}$ capture in the same step.

Finally, we will conduct a pilot-scale demonstration of this commercially ready MR to replace existing two-stage packed bed WGS reactor; thus, hydrogen separation, $\mathrm{CO}_{2}$ capture, and contaminant removal can be integrated into the power generation system with the proposed hardware and process. 


\section{BIBLIOGRAPHY}

1. Satterfield, C. N., Heterogeneous Catalysis in Practice, McGraw-Hill, 1980.

2. Bracht, M., etc., "Water-gas-shift Membrane Reactor for CO2 Control in IGCC Systems:

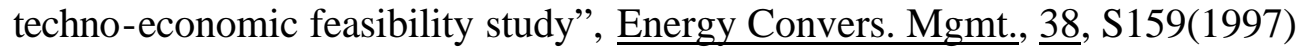

3. Ciora, R. J., and P. K.T. Liu, "Carbon Membranes - Perspective from a Membrane Manufacturer", $200018^{\text {th }}$ Annual Membrane/Separations Technology and Planning Conference, Newton, MA.

4. Criscuoli, A., A. Basile, E. Drioli, O. Loiacono, "an Economic Feasibility Study for Water Gas Shift Membrane Reactor", J. Memb. Sci., 181, 21(2001)

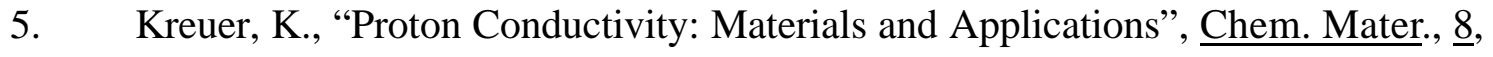
610(1996)

6. Gallaher, G. R., Liu, P. K.T., etc., CatCon '94, June 26-28, 1994, Philadelphia, PA

7. Julbe, A., d. Farrusseng, C. Guizard, "Porous Ceramic Membranes for Catalytic Reactors- Overview and New Ideas", J. Memb. Sci, 181, 3(2001)

8. Liu, P.K.T., and Wu, J.CS, US Patent 5,415,891, May 16, 1995

9. Liu, P., et. Al., "High Temperature Fluid Separations using Ceramic Membrane Device", US Patent 5,611,931 (March 18, 1997).

10. Padro, C.E.G. and V. Putsche, "Survey of the Economics of Hydrogen Technologies", NREL/TP-570-27079, September 1999.

11. Wu, J.C.S., Sabol, H., Smith, G.W., Flowers., D. F., Liu, P.K.T., "Characterization of Hydrogen-Permselective Microporous Ceramic Membranes", J. Memb.Sci., $\underline{96}$, 275(1994) 


\section{LIST OF ACRONYMS AND ABBREVIATIONS}

WGS: $\quad$ water-gas-shift reaction

LTS: $\quad$ low temperature shift

HTS: high temperature shift

MR: membrane reactor 


\section{APPENDICES}

Pilot testing facility used for hydrogen recovery from $\mathrm{H} 2 / \mathrm{CO}$ mixture.

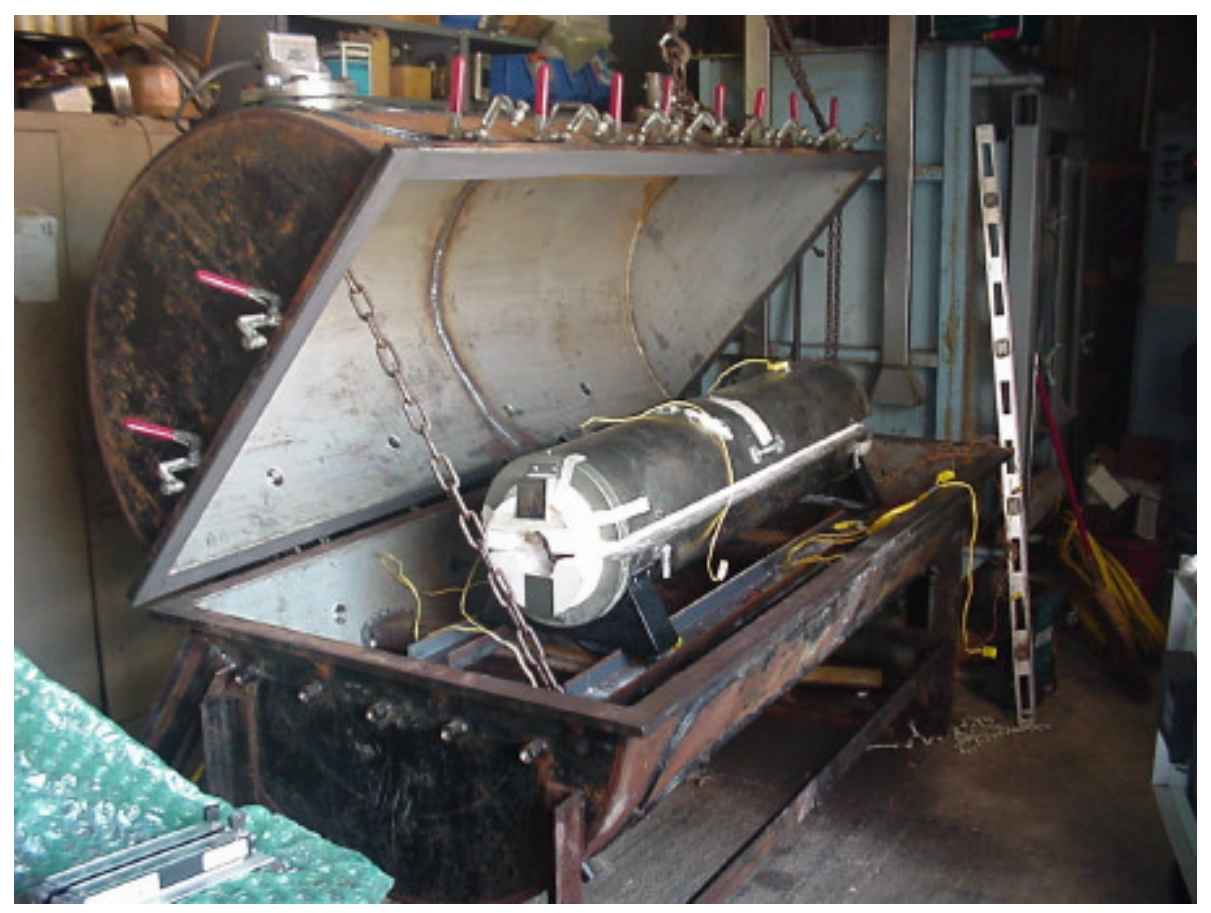

